\title{
Sintomas Denunciadores do "Desvio de Poder".
}

\author{
José Cretella Júnior \\ Professor Titular de Direito Administrativo da Fa- \\ culdade de Direito da Universidade de Săo Paulo.
}

Sumário: 1. Introdução. 2. Contradição com atos posteriores. 3. Contradição do ato com atos anteriores. 4. Motivação excessiva. 5. Motivação contraditória. 6. Motivaçāo insuficiente. 7. Alteraçāo dos fatos. 8. Ilogicidade manifesta. 9. Manifesta injustiça. 10. Disparidade de tratamento. 11. Derrogaçāo de normas internas. 12. Contribuição francesa. 13. Presença de sintomas no direito brasileiro. 14. Conclusão.

\section{Introdução.}

"Desvio de poder" é o uso indevido que o administrador faz do poder discricionário de que é detentor para atingir fim diverso do que a lei assinalará. Ou é o uso indevido que a autoridade administrativa faz do poder que lhe é conferido para atingir finalidade diversa daquela que a lei preceituara (cf. nosso Do desvio de poder, 1964, p. 27; Tratado de direito administrativo, 1966, v. II, p. 250; Curso de direito administrativo, 4. ${ }^{a}$ ed., 1975, p. 349).

Provado o "desvio", impõe-se a anulação do ato administrativo, eivado desse defeito, o que pode ocorrer quer "de ofício", pela própria Administração, em virtude do princípio da auto-tutela administrativa ou de solicitação do interessado, quer pelo Poder Judiciário, quando o prejudicado provoca 0 exame da finalidade do ato lesivo a seus direitos. 
No entanto, a prova é difícil, na maioria dos casos; impossível mesmo, em outros, porque o administrador, que agiu de má-fé, procura mascarar a medida legal "dolosa", envolvendo-a com o manto inatacável da legalidade.

"Casos há", escreve Nunes Leal, "em que fica patenteada a ausência da conveniência pública, pela manifesta preponderância do favoritismo, da perseguição, ou do puro proveito pessoal do agente. Em tais casos, a prova é sempre difícil, freqüentemente impossível, o que reduz as consequiências práticas do princípio. Algumas vezes, porém, ela ressalta, ostensivamente, do conjunto de evidências documentais. Em situações dessa natureza, pode o Judiciário proclamar que a autoridade exorbitou, abusando do seu poder discricionário; agiu, portanto, arbitrariamente" (Nunes Leal, Problemas de direito público, 1960, p. 292) .

Certos "sintomas" (índices, indícios, traços), entretanto, podem denunciar a "distorção", fornecendo fundamento seguro para a anulação do ato viciado.

Tais sintomas ainda não levados em conta $\mathrm{e}$, muito menos, nem sistematizados entre nós, têm sido apontados pela doutrina italiana e francesa, principalmente com apoio nas construções pretorianas do Conselho de Estado dos respectivoṣ países.

Diante de casos práticos, instado a manifestar-se, o Conselho de Estado italiano, em fins do século passado, e inícios deste, seguindo a mesma orientação fixada pelo Conselho de Esstado francês, foi com esforço admirável e continuado construindo a teoria do "desvio de poder", enumerando, depois, casuisticamente, as hipóteses concretas em que o diagnóstico daquela ilegalidade poderia ser feito (cf. Mortara, Comentario, $4 .^{\mathrm{a}}$ ed., v. I, p. 482 e seguintes, nota 1, citado por Alessio, Istituzioni di diritto amministrativo italiano, $4 .^{2}$ ed., 1949, v. II, p. 245, nota 1).

Com apoio na jurisprudência do Conselho de Estado francês e italiano, bem como na consagração doutrinária dos 
autores mais representativos desses dois países, é possível apontar os seguintes sintomas, suficientes para suscitar o exame do ato administrativo perante a Administração ou perante o Judiciário, pedindo o reconhecimento do "desvio" e a conseqüente anulação da medida lesiva ao direito subjetivo público do administrado, em virtude da arbitrariedade do administrador. Entre esses "índices", "indícios" ou "sintomas", é possível arrolar os seguintes: contradição do ato com atos ou medidas posteriores; contradição do ato com atos ou medidas anteriores; motivação excessiva, contraditória ou insuficiente; alteração dos fatos; ilogicidade ou injustiça manifesta; disparidade de tratamento; derrogação de norma interna; precipitação na edição do ato; caráter sistemático de certas proibições; circunstâncias locais anteriores à edição do ato; convergência de feixe de sintomas; caráter geral dado a medida que deveria ter permanecido particular.

Esses os mais significativos traços ou sintomas, apontaclos pela doutrina e que, levados em conta, caracterizam a figura do desvio de poder.

Examinemos um a um os sintomas referidos, procurando, na medida do possível, exemplos ilustrativos no direito brasileiro, mediante análise da jurisprudência consagrada pelos nossos tribunais.

\section{Contradição do ato com atos posteriores.}

Dentre as várias hipóteses inventariadas pela doutrina italiana (ZANOBINI, Corso, 6. ${ }^{\mathrm{a}}$ ed., 1960, v I, p. $250-251$ e Corso, 6. ${ }^{\mathrm{a}}$ ed., 1948, v. II, p. 142 a 144; Alessio, Istituzioni, 4. ${ }^{\mathrm{a}}$ ed., 1949, v II, p. 244; LANDi e Potenza, Manuale, 2. ed., 1963, p. 272 a 275), a "contradição do ato com atos posteriores" envolve o problema de descobrir com nitidez a efetiva vontade da Administração, quando vários atos, simultâneos ou sucessivos, concretizam objetivos entre si contraditórios (Landi e Potenza, Manuale, 2. ${ }^{a}$ ed., 1963, p. 274) 
Caso típico de contradição flagrante do ato com atos posteriores apreciou o Tribunal de Alçada de São Paulo quando autoridade local demitiu funcionário público, nomeado em caráter efetivo, a pretexto de que as finanças do Município periclitavam, em razão do excessivo número de servidores admitidos.

Entretanto, vinte e quatro dias após, dezenas de nomeações eram feitas pela mesma autoridade que editara 0 ato demissório, inclusive duas para cargos de encarregado de serviço, de padrão igual ao do agente público demitido.

O Tribunal, apreciando o caso, concluiu: "na espécie, demitido o autor por força de ato que teria como finalidade a economia dos cofres públicos, outras pessoas foram nomeadas para cargos idênticos. Houve, pois, desvio de poder. $\mathrm{O}$ ato demissório, assim, por mais esse fundamento, deve ser considerado nulo, impondo-se, como conseqüência, a procedência da ação" (TASP, . 1961, rel. Rodrigues De AlcKMin, em RDA 70/172-174)

\section{Contradição do ato com atos anteriores .}

A contradição do ato com manifestação anterior de vontade do mesmo órgão é apontada por ZANoBini (Corso, 6. ${ }^{\mathbf{a}}$ ed., 1950, v. I, p. 251) como sintoma inequívoco da ocorrência de desvio de poder. "Assim, a punição disciplinar, aplicada a alguns funcionários em virtude de fato que, em circunstância anterior, a mesma autoridade não considerara punível; ou a licença forçada ou demissão de funcionário, por incapacidade ou por escasso rendimento, quando, pouco tempo antes, eram confiados ao mesmo agente encargos delicados e importantes e fora manifestada a satisfação da autoridade pelo modo louvável com que o funcionário os houvera resolvido" (ZANobini, Corso, 6. a ed., 1950, v. I, p. 251; Aldo Bozzi, Istituzioni di diritto pubblico, 2. ${ }^{a}$ ed., 1966, p. 331)

Ugo ForTi enumera quatro sintomas típicos para o diagnóstico do desvio de poder, ou seja, (a) o "travisamento" dos 
fatos, (b) a manifesta injustiça, (c) a motivação ilógica, contraditória ou irracional e (d) a contradição da medida com ato administrativo anterior (cf. UGo ForTI, Lezioni di diritto amministrativo, 1950 , v. II (parte generale: il rapporto-la teoria degli atti), p. 192-193.

A contradição da medida com atos anteriores da Administração é também ilustrada por UGo FoRTI com a hipótese de exoneração de funcionário, fundada em escasso rendimento se a Administração sempre lhe reconheceu o zelo, a profícua atividade, em contraste flagrante com a demissão (Lezioni di diritto amministrativo, 1950, v. II, p. 192-193).

\section{Motivação excessiva .}

E nos motivos determinantes do ato que o desvio de poder se revela (cf. Maurice Hauriou, Précis de diroit administratif et de droit public, 11. a ed., 1927, p. 421) afirma Hauriou. Ora, a motivação, ou seja, a explicitação dos motivos que levaram a Administração a editar o ato (ALESSI, Sistema istituzionale del diritto amministrativo, 1953, p. 257 e nosso Tratado, 1966, v. II, p. 207), pode ser inexistente, insuficiente, exagerada ou contraditória. Neste parágrafo, cabe o exame da motivação exagerada ou excessiva, típica do ato administrativo eivado do desvio de poder. Não convencido da autenticidade do ato, o administrador, como que temendo a força da opinião pública, procura defender-se "a priori", justificando, em demasia, a medida editada.

Pietro Gasparri, no verbete "eccesso di potere", com que ilustrou as páginas da Enciclopedia del diritto, vol. 16, "sub voce", aponta de modo expresso a superabundância de motivação como um dos sintomas inequívocos do desvio de poder. "Muitas vezes o excesso de polder é revelado pela superabundância de motivação. Quando o editor do ato apresenta, como justificação, uma série de fatos e de considerações prolixas e não concludentes, é fundada a suspeita de que sua decisão decorre de uma opção, cujos verdadeiros motivos é 
preferível que se conservem ocultos" (Pietro Gasparri, Enciclopedia del diritto, v. 16, "sub voce" eccesso di potere).

Em outra obra, Pietro Gasparri salienta que "cumpre não confundir a perplexidade ou contraditoriedade da motivação com a simples superabundância dos motivos adotados, quando estes não são incompatíveis entre si. Certo que também, em tais casos, pode surgir suspeita sobre a pureza da apreciação daquele que editou o ato. O órgão que tem motivo claro e suficiente para editar determinado ato não sente a necessidade de reforçar esse motivo com considerações acessórias; pode pensar-se que, se o faz, é porque não se sente totalmente seguro com nenhum dos motivos tomados em si e por si, isoladamente" (Pietro Gasparri, Corso di diritto amministrativo, v. III, Le disorganizzazioni e le disfunzioni amministrative, 1956, p. 162)

Exemplo claro de decreto expropriatório, editado com desvio de poder, está no ato de n. ${ }^{\circ} 23.529$, de 5 de julho de 1973, publicado no Diário Oficial de Salvador, Bahia, no dia 6 do mesmo mês e ano, declarando de utilidade pública, em caráter de urgência, para efeito de desapropriação, imóvel residencial particular para que nele se instalasse escola-parque para crianças excepcionais.

Ao invés de declarar simplesmente a utilidade pública, cm caráter de urgência", fundamentando-se no diploma expropriatório em vigor e capitular a hipótese, no respectivo inciso, do art. 5..$^{\circ}$ do Decreto-lei n. ${ }^{\circ} 3.365$, de 21 de junho de 1941, o editor do ato estendeu-se nos "consideranda", superabundantemente, explicando e re-explicando a necessidade da medida, o que caracteriza o desvio de poder por "excesso de motivação", como demonstrou, de maneira irretorquível o professor Manoel Gonçalves Ferreira Filho, solıcitado a manifestar-se a respeito, mediante Parecer jurídico (cf. Parecer, em RDA 118/431) "Corrobora essa conclusão a presença de um dos sinais do abuso de poder. A motivação do desvio é excessiva. Ora, nisso está, segundo a lição de GAS- 
pARRI, um dos sintomas do excesso ou desvio de poder" (Manoel Gonçalves Ferreira Filho, Parecer, em rda $118 / 435)$.

\section{Motivação contraditória .}

$\mathrm{O}$ ato administrativo exprime a vontade da Administração. Nos motivos, está a razão de ser da decisão. A motivação contraditória deixa o intérprete perplexo a respeito da verdadeira razão inspiradora do administrador. A doutrina italiana é unânime ao apresentar a motivação contraditória como sintoma inequívoco da presença do desvio de poder (cf. Alessi, Diritto amministrativo, 1949, v. I, p. 293; Zanobini, Corso di diritto amministrativo, 6. ${ }^{\mathrm{a}}$ ed., 1948, v. II, p. 144 e Corso, 6. ${ }^{\mathrm{a}}$ ed., 1950, v. I, p. 251; LANdi e Potenza, Mamuale di diritto amministrativo, 2. ${ }^{\mathrm{a}}$ ed., 1963, p. 273-274; Ugo Forti, Lezioni di diritto amministrativo, 1950, v. II, p. 192; Arnaldo de Valles, Elementi di diritto amministrativo, 3. a ed., 1965, p. 171)

"A ilogicidade ou contraditoriedade do ato é revelada pelo contraste insanável entre várias de suas partes, como, por exemplo, entre os "diversos incisos da motivação", ou entre a "motivação" e o "dispositivo" Assim, a deliberação de Comissão Disciplinar que, depois de haver excluído a responsabilidade do funcionário por inexistência de culpabilidade, acaba propondo, depois, no Parecer, a aplicação de pena" (LANdi e Potenza, Manuale di diritto amministrativo, 2. ${ }^{\mathrm{a}}$ ed., 1963, p. 273-274) ZANOBINI emprega também a expressão ilogicidade manifesta para designar a "falta de nexo lógico entre os vários motivos ou entre a motivação e o dispositivo do ato" (cf. Corso, 6. a ed., 1950, v. I, p. 251 e Corso, 6. "a ed., 1948, v. II, p. 144).

Arnaldo de Vales menciona neste sintoma sob a epígrafe de "falta de nexo lógico entre premissas e ato", hipótese em que "o ato se apresenta com uma causa que não é a de- 
dução lógica dos motivos e se funda numa contradição lógica, que não pode ser protegida pelo direito" (Elementi di diritto amministrativo, 3. ${ }^{\mathrm{a}}$ ed., 1965 , p. 171)

No citado caso da desapropriação de mansão particular, na Bahia, para a instalação, no imóvel, de escola-parque para excepcionais, o desvio de poder ficou também caracterizado pela ilogicidade manifesta entre dois dos motivos mencionados, na justificação, o que foi assim apreciado pelo professor Manoel Gonçalves Filho (Parecer, em Rda 118/435), manifestando-se a respeito: "A menção deste segundo motivo serve, entretanto, para colocar sob suspeita o primeiro, se outras razões não houvesse para tanto. Como duas cogitações tão díspares, o interesse dos excepcionais e a preservação da beleza citadina, podem confluir numa expropriação, sem que se suspeite, de que tais motivos foram indevida e falsamente invocados, ou, ao menos, um deles?"

Desse modo, a contradição flagrante entre dois motivos é sintoma que deve ser levado em conta para o diagnóstico do desvio de poder.

\section{Motivação insuficiente.}

Motivação insuficiente é outro sintoma apresentado pela doutrina (ALEssi, Diritto amministrativo, 1949, v. I, p. 293; Aldo Bozzi, Istituzioni di diritto pubblico, 2. ${ }^{\text {a }}$ ed., 1966, p. 331)) para a positivação de ocorrência de desvio de poder, como, por exemplo, no Brasil, se decretasse desapropriação apenas fundada, genericamente, na utilidade pública, deixando o expropriante de indicar, de modo específico, o inciso correspondente do Decreto-lei n. ${ }^{\circ}$ 3.365, de junho de 1941.

\section{Alteração dos fatos.}

A doutrina italiana aponta o "travisamento" (= alteração, adulteração, deformação) dos fatos como sintoma típico do desvio de po'der (Cino Vitta, Diritto amministrativo, 3. ${ }^{\text {a }}$ 
ed., 1949, v. I, p. 431; Aldo Bozzr, Istituzioni dí diritto pubblico, 2. a ed., 1966, p. 331; Alessi, Diritto amministrativo, 1949, p. 293; Zanobini, Corso di dititto amministrativo, 6. ${ }^{\text {a }}$ ed., 1950, v. I, p. 251 e Corso, 6. ${ }^{\text {a }}$ ed., 1948, v. II, p. 143; LANDi e Potenza, Manuale di diritto amministrativo, 2. ${ }^{a}$ ed., 1963 , p. 273; Alessio, Istituzioni di diritto amministrativo italiano, 4. ${ }^{\mathrm{a}}$ ed., 1949, v. II, p. 245 , nota 1 , citando Mortara; LENTINI, Istituzioni di diritto amministrativo, 1939, v. II, p. 20, veja Forti, Lezioni, 1950, v. II, p. 192)

"A mim me parece", escreve CINo VITTA, "que a alteração (travisamento) pode melhor ser considerada como um dos sintomas que acusarão a existência do desvio, entendendo-se como "travisamento" a averiguação ou a avaliação dos fatos, em geral, de modo artificial, com a finalidade de submetê-los à aplicação de preceito de lei, sob o qual, de outro modo, não teriam sido enquadrados. Célebre o exemplo de ordem de fechamento de edifício de habitação por insalubridade, alterando-se para isso os fatos, quando na verdade a casa é modelo de salubridade. Mais facilmente a alteração pode confundir-se com o vício de inoportunidade, no mérito do ato administrativo, e os limites dele vão assinalados com refinado senso jurídico. $\mathrm{O}$ ato inoportuno quando não pareça justificado por suficientes motivos de fato, embora subsistindo alguns dos fatos que a lei levou em conta, ao passo que é viciado por travisamento (alteração), quando nenhum dos fatos apresentados corresponde à realidade e esteja assim ausente toda exigência de interesse público" (CIno VITTA, Diritto amministrativo, 3. ${ }^{\mathrm{a}}$ ed., 1949, v. II, p. 431-432).

"Ocorre a alteração dos fatos quando, na motivação do ato, são afirmados, como seus pressupostos, fatos insustentáveis, ou são negados fatos reais. À alteração é equiparada a consideração dos fatos afirmados; trata-se, ao contrário, de valoração inoportuna ou injusta, saindo-se do vício de legitimidade para entrar no vício de mérito" (ZANobInI, Corso, 6. " "ed., 1950, v. I, p. 251). "Ocorre o desvio de poder por 
alteração (travisamento) dos fatos sempre que o ato é editado sobre pressuposto da existência ou da inexistência dos fatos, que dos atos resultam, de modo certo, inexistente ou subsistente. Ao contrário, não se dá o travisamento, quando o ato resulta de apreciação discricionária da Administração a respeito de fatos existentes: um juízo sobre tal apreciação se resolve em exame de mérito" (ZANobini, Corso, 6. a ed., 1948, v. II, p. 143) .

Com base na jurisprudência italiana Aldo Bozzi ressalta que a circunstância de ocorrer o travisamento (ato baseado em pressuposto da existência ou inexistência dos fatos que resultam, ao contrário, inexistentes ou existentes) é um dos sintomas típicos do desvio de poder (cf. Istituzioni, 2. a ed., 1966, p. 331)

LANDi e Potenza ressaltam que a alteração e a valoração errônea dos fatos influem sobre a vontade, ocorrendo quer quando a Administração, ao editar o ato, considerou, de modo errôneo, como existentes, fatos inexistentes, ou viceversa, quer quando atribuiu aos fatos significado errôneo, ilógico ou irracional. Considera-se viciado de alteração dos fatos, por exemplo, o ato que aceita a demissão de funcionário, baseado no pressuposto errôneo: que o funcionário a tenha apresentado; considera-se de errônea valoração o ato que considera injustificada a ausência do funcionário, quando já foi devidamente comprovado que ela ocorreu, em virtude de doença. Não deve confundir-se com a valoração errônea a valoração inoportuna ou injusta, que pode originar vício de mérito, mas não vício de legitimidade. Assim, não se verifica erro, mas apenas inoportunidade ou injustiça se a Administração, apurando de modo preciso as circunstâncias de uma infração disciplinar lhe atribui, para fins de aplicação da pena, excessiva gravidade" (LANDi e Potenza, Manuale di diritto amministrativo, 2. ${ }^{\text {a }}$ ed., 1963 , p. 273)

Silvio Lessona enquadra esta hipótese no erro de fato, consistente no "haver posto na base do ato administrativo 
fatos inexistentes ou no em haver considerado inexistentes atos existentes" (Introduzione al diritto amministrativo e sue strutture fondamentali, 1960, p. 87).

\section{Ilogicidade manifesta.}

A ilogicidade manifesta - perplexidade ou incongruência cios motivos invocados para suporte do ato - é outro dos sintomas apresentados pelos autores para a denúncia do desvio de poder (Aldo Bozzr, Istituzioni di diritto pubblico, 2. ${ }^{\text {a }}$ ed., 1966, p. 331; Zanobini, Corso, 6. ${ }^{\mathrm{a}}$ ed., 1950, v I, p. 251 e Corso, 6. ${ }^{a}$ ed., 1958, v. II, p. 144) Consiste a ilogicidade manifesta "na ausência de nexo lógico entre os vários motivos oli entre a motivação e o dispositivo do ato" (ZANOBINI, Corso, 6. a ed., v. I, p. 251) ou "na ausência de nexo lógico entre os motivos e o dispositivo do ato ou na contradição entre as várias partes dele" (ZANobINI, Corso, 6. ${ }^{a}$ ed., 1948, v II, p. 144).

Silvio Lessona também inclui a ilogicidade do ato entre os sintomas do desvio de poder, "quer quando na medida se dispõe em contraste com os motivos adotados para justificar o próprio ato, quer quando os motivos, sendo perplexos ou contraditórios, não permitem saber se a Administração agiu de modo correto para a realização do interesse público" (Introduzione al diritto amministrativo e sue strutture fondamentali, 1960, p. 87)

\section{Manifesta injustiça.}

A injustiça manifesta, acolhida pela jurisprudência italiana para denunciar o desvio de poder, designa a diversidade ou disparidade de tratamento atribuída a situações idênticas (ZAnobini, Corso, 6. ${ }^{a}$ ed., 1948, v. II, p. 143) ou, em outros casos, o gravame imposto no interesse privado, sem a suficiente razão de interesse público. Como se vê, no primeiro caso, o vício pode reduzir-se ao da contradição, no segundo caso, tal 
vício parece invadir o campo do mérito administrativo e a decisão não pode ser aprovada. Só quando a ausência do interesse público pode ser demonstrada com base em elementos gue integram o ato ou atos a ele ligados, pode o vício denominar-se de ilegitimidade e levar ao desvio de poder (Zanobini, Corso, 6. ${ }^{\mathrm{a}}$ ed., 1948, v. II, p. 143-144).

Landi e Potenza observam que este sintoma é raríssimo, porque, regra geral, a injustiça é vício de mérito. Como exemplo, apresenta o caso da dispensa de serviço de funcionário por motivo de escasso rendimento, quando, na realidade, a causa da anomalia reside em acidente originado do próprio serviço (Manuale di diritto amministrativo, 2. ${ }^{\mathrm{a}}$ ed., 1963, p. 274)

Admite-se tal modalidade de desvio de poder, quando se considera que a Administração deve agir como o homo eticus, devendo, então, exercer-se o poder que lhe é atribuído de acordo com a mais estrita equidade, ou seja, a "imparcialidade da Administração", de que fala o artigo 97 da Constituição italiana (cf. Silvio Lessona, Introduzione al diritto amministrativo e sue strutture fondamentali, 1960, p. 88) .

\section{Disparidade de tratamento.}

Landi e Potenza, ao contrário de Zanobini que identifica os sintomas manifesta injustiça e disparidade de tratamilento (Zanobini, Corso, 6. ${ }^{\mathrm{a}}$ ed., 1948, v. II, p. 143 e 144), mencionam as duas hipóteses, ilustrando-as e definindo-as de modo diverso e bem nítido. Na realidade, a disparidade de tratamento é espécie ou forma de injustiça, verificando-se "quando a Administração, em presença de perfeita identidade de condições subjetivas e objetivas, adota medidas diferentes, como na hipótese em que, na apuração de determinada infração disciplinar e de grau igual de responsabilidade, seja um dos funcionários absolvido e o outro punido" (LANDI e Potenza, Manuale di diritto amministrativo, 2.a ed., 1963, p. 274) . 
Aldo Bozzi nota que a manifesta e grave injustiça é situação que se inclui em outras hipóteses (ilogicidade, disparidade de tratamento) ou constitui vício de mérito e não de legitimidade, já que implica apreciação do conteúdo e da oportunidade do ato (Istituzioni di diritto publico, 2. ${ }^{a}$ ed., 1966, p. 331). (cf. Ugo ForTI, Lezioni di diritto amministrativo, 1950, v. II, p. 192).

\section{Derrogação de norma interna.}

As normas internas (cf. Silvestri, L'attivitá interna della pubblica amministrazione, 1950 , p. 186) não se equiparam, é claro, às normas jurídicas no sentido substancial e, assim, sua transgressão não pode entrar no conceito de violação da lei (cf. LANdi e Potenza, Manuale di diritto amministrativo, 2. ${ }^{a}$ ed., 1963, p. 274) Ora, "a derrogação injustificada, em um caso particular, de disposições internas de caráter geral, editadas pela Administração, como, por exemplo, a violação de circulares é também sintoma típico de desvio de poder" (Aldo Bozzı, Istituzioni di diritto pubblico, 2. a ed., 1966, p. 331).

"Quando a Administração disciplinou a própria atividade com tal espécie de normas, entende-se que tenha individuado as modalidades mais oportunas para a consecução do interesse público e, pois, se tenha auto-limitado, no sentido de não poder agir, nos casos particulares, de modo diverso daquele que estabelecera, na norma interna (circular, instrução), de modo geral" (LANdi e Potenza, Manuale di diritto amministrativo, $2 .^{\mathrm{a}}$ ed., 1963 , p. 275 ) .

De acordo com o princípio "suporta a lei que fizeste", erigida uma norma como diretriz de determinado setor da $\Lambda$ dministração, vale ela de modo igual para todos, não se admitindo, a não ser por desvio de poder, seja derrogada para atender a caso particular. 


\section{Contribuição francesa.}

Os diferentes sintomas acima, catalogados e analisados pela doutrina italiana, representam a síntese de casos concretos, decididos pelo Conselho de Estado da Itália.

A doutrina gaulesa, também fundamentada em casos apreciados pelo Conselho de Estado da França, procura sisteniatizar as hipóteses dos traços reveladores do desvio de poder, denominados pelos autores franceses de "indícios", "índices" ou "provas"

Waline observa que "é fácil, com efeito, compreender que quando o administrador usa dos poderes de que dispõe para atingir fim inconfessável não tem a ingenuidade de confessá-lo. Disfarça, então, os verdadeiros motivos do ato e apresenta oficialmente um pretexto legal. Trata-se de desmascarar o embuste, o que nem sempre é fácil" (Waline, Traité élémentaire de droit administratif, 6. ${ }^{\mathrm{a}}$ ed., 1952, p. 144), "mas muito mais difícil ainda é conhecer a verdadeira intenção do autor do ato cuja legalidade é discutida. Com efeito, quando a autoridade administrativa comete o desvio de poder, é porque agiu de má fé, sabendo muito bem que traiu a intenção do legislador, pelo que não tem a inocência de indicar as razões inconfessáveis que lhe inspiraram o ato. A autoridade dissimula os móveis verdadeiros que a impeliram, devendo o juiz analisar todas as circunstâncias que cercaram a edição do ato. Esta prova é dificílima de ser feita" (Waline, Droit administratif, 9. ${ }^{\mathrm{a}}$ ed., 1963, p. 481)

Entre os índices ou sintomas denunciadores do desvio de poder a doutrina francesa, baseada em decisões do Conselho de Estado, aponta os seguintes: (a) pressa com que o ato foi editado, (b) inexistência dos motivos apresentados pelo administrador para justificar a decisão tomada, (c) desigualdade de tratamento dos interessados, (d) caráter sistemático de certas interdições, (e) caráter geral atribuído a medida que 
deveria permanecer particular, $(f)$ circunstâncias locais que antecederam a edição do ato.

"No plano prático", salienta Francis-PAul Bénort, "o desvio de poder suscita delicadíssimo problema de prova. Tratando-se de perscrutar intenções, a dificuldade não causará espanto. Com muita sabedoria o juiz administrativo exige, de qualquer modo, provas palpáveis, quer resultantes da própria redação do ato - hipótese rara, mas que pode ocorrer porque, inadvertidamente, o autor da decisão fornece, às vezes, elementos que caracterizam a ilegalidade de suas intenções -, quer do dossier, ou seja, do cotejo do ato impugnado com outros documentos" (Le droit administratif français, 1968, p. 545)

RIVERo observa que uma das dificuldades para caracterizar o desvio de poder radica "no terreno da prova. A' intenção é elemento psicológico, difícil de apreender, salvo quando o autor o declara abertamente, o que será tanto mais raro quanto menos confessável" (Droit administratif, 7 a ed., 1975, p. 251-252 e Lemasurier, La preuve dans le détournement de pouvoir, na Revue de droit public et de la science politique, 1959, p. 36)

"Mais difícil de provar do que os outros vícios do ato administrativo, porque se trata de descobrir a intenção psicológica de seu autor" (VeDEI, Droit administratif, 5..$^{\text {a }}$ ed., 1973, p. 609), o desvio de poder admite a prova indireta, já que o administrador raramente iria contribuir com a prova direta, confessando o motivo real ou confidenciando as intenções que o impeliram a editar o ato (VEDEL, Droit administratif, 5. a ed., 1973, p. 610)

Pressa na edição do ato é sintoma acolhido pelo Conselho de Estado francês, como ocorreu, por exemplo, na decisão proferida em 3 de março de 1939, quando diretor, que acabara de ser nomeado e nem tomara posse do cargo, assinou o ato e mandou executá-lo com precipitação anormal, no dia 
seguinte ao em que fora empossado (Waline, Traité élémentaire de droit administratif, 6. ${ }^{\mathrm{a}}$ ed., 1952, p. 144 e Droit administratif, 9. ${ }^{\mathrm{a}}$ ed., 1963, p. 482).

Inexistência dos motivos alegados pelo administrador, como, por exemplo, proibição de procissões, nas ruas, sob o falso pretexto de que trariam perturbações à ordem pública, é outro dos sintomas do desvio de poder apontado pela doutrina francesa, com base na realidade submetida à decisão do Conselho de Estado (decisão de 18 de agosto de 1944, citado por Waline, Traité élémentaire, 6. ${ }^{\mathrm{a}}$ ed., 1952, p. 144).

Aos demais sintomas, arrolados no início deste parágrafo, a doutrina gaulesa acrescenta outros - peças escritas, circunstâncias nas quais interveio o ato, inexatidão dos motivos alegados (cf. RIvero, Droit administratif, $7^{\mathrm{a}}$ ed., 1975, p. 252) - que deixam transparecer o fim verdadeiro que o administrador pretendia alcançar. "O magistrado procura menos uma prova manifesta do que uma convicção, que pode resultar de um feixe de indícios convergentes" (Rivero, Droit administratif, $7^{\text {a }}$ ed., 1975, p. 252).

\section{Presença de sintomas no direito brasileiro.}

Diante dos tribunais brasileiros têm sido levados para apreciação inúmeros atos administrativos eivados de desvio de poder e, em especial, decorrentes do exercício do poder de polícia e da hierarquia.

O poder de polícia, incidindo sobre inúmeras áreas de exercício de direitos do particular, inclusive sobre as faculdades inerentes ao direito de propriedade, adquire especial relevância no que se refere ao decreto expropriatório, ato administrativo que sob o disfarce de interesse público serve para a satisfação de caprichos ocultos do administrador.

O poder hierárquico, recaindo sobre todo o funcionalismo, serve de constante pretexto para a prática do desvio de 
poder, já que oferece amplas possibilidades para que o superior cometa abusos sobre os subordinados, aplicando-lhes sanções por motivos pessoais e não objetivando o bom andamento do serviço público.

Ao contrário, porém, do que se verifica com os tribunais dos países que admitem o contencioso administrativo, entre os quais a França e a Itália, cujos magistrados, especializados em questões administrativas, reconhecem a figura do desvio de poder mediante a interpretação rigorosa de "índices", "indícios", "sintomas" ou "feixes convergentes de indícios", que lhes fornece elementos para a convicção, por ocasião do ato de julgamento, no Brasil, país em que vigora o princípio da "una lex, una jurisdictio", o desvio de poder é mais intuído, de maneira global, do que diagnosticado mediante a análise de índices científicos, denunciadores da arbitrariedade.

Sendo a intenção elemento interior de apreensão difícil, a não ser quando o autor o revela por inadvertência ou de modo espontâneo, o diagnóstico do desvio de poder tem de ser empreeendido pela prova indireta, refletida nos sintomas repontáveis aqui e ali, denunciados pela parte prejudicada e apreciados pelo juiz.

No caso concreto, citado no parágrafo segundo deste trabalho, o abuso da hierarquia culminou com a demissão ilegal, mas o colegiado julgador, com fundamento no sintoma indiscutível - "contradição do ato com atos posteriores" -, anulou o ato demissório, editado com desvio de poder, já que sua base (economia do erário) entrava em choque com providência posterior (admissão de outros funcionários, inclusive para o mesmo cargo), o que configura sintoma inequívoco do arbítrio administrativo, traduzido na regra dos "dois pesos, duas medidas".

Em outro caso concreto, mencionado no parágrafo quarto deste trabalho, o arbítrio administrativo culminou com decreto expropriatório, fundado em móvel pessoal, objetivando 
vindicta, revelado pelo sintoma típico da motivação excessiva, superabundante, prolixa, arquitetada para disfarçar, sob o manto legal do interesse público, as intenções privadas e inconfessáveis do administrador.

\section{Conclusão.}

Procuramos, neste trabalho, aproveitar a experiência francesa e italiana, consagrada pelo Conselho de Estado daqueles países e exposta depois sistematicamente pela doutrina. Confrontando tais resultados com a realidade brasileira é possível um entendimento maior desta figura iuris do direito administrativo, admitida hoje, sem reservas, entre nós.

Se desvio de poder é o uso indevido que o administrador faz do poder discricionário de que é det'entor para concretizar "fim" diferente daquele que a lei fixara, o ato administrativo, editado com essa anomalia, é nulo, mas a prova da ilegalidade nem sempre é possível e, por vezes, mostra-se difícil, porque tem de revelar aspecto psicológico do autor e, assim como certas moléstias insidiosas se ocultam ante os olhos perscrutadores do cientista, só se revelando mediante análise e interpretação de índices ou traços indiretos, assim também cumpre ao intérprete do ato administrativo, eivado de desvio de poder, chegar ao momento de interioridade da autoridade arbitrária, disfarçado sob o manto inatacável da legalidade.

$\mathrm{O}$ animus do administrador, por mais arraigado que seja, pode ser denunciado por sintomas indiscutíveis, inventariados pela doutrina clássica de outros países e assim enumerados: (a) contradição do ato com atos ou medidas posteriores, (b) contradição do ato com atos ou medidas anteriores, (c) motivação excessiva, (d) motivação contraditória, (e) motivação insuficiente, $(f)$ alteração (= travisamento) dos fatos, (g) ilogicidade manifesta, (h) injustiça manifesta, (i) disparidade de tratamento, (j) derrogação de norma interna, (I) precipitação na edição do ato, $(m)$ caráter sistemático de certas 
proibições, $(n)$ circunstâncias locais que precederam a edição do ato, $(o)$ convergência de feixe de indícios, $(p)$ caráter geral dado a medida que deveria ter permanecido particular.

Um (ou mais de um) desses traços basta para o diagnóstico do desvio de poder: o sintoma é a prova indireta do arbítrio administrativo, concretizado na figura do desvio de poder.

Denunciado o desvio de poder pela parte prejudicada, a autoridade judicante pode motivar a razão de decidir em um dos sintomas acima enunciados, inventário empreendido pela mais autorizada doutrina estrangeira, com base em casos concretos, julgados, em definitivo, pela mais alta instância dos tribunais administrativos. 